\title{
Carotid Intima-Media Thickness in African Patients with Critical Lower Limb Ischemia Infected with the Human Immunodeficiency Virus
}

Martin Brand ${ }^{2 *}$, Angela $\mathrm{J}_{\text {Woodiwiss }}{ }^{\star *}$, Frederic Michel ${ }^{1}$, Hendrik L Booysen ${ }^{1}$, Olebogeng HI Majane ${ }^{1}$, Muzi $\mathrm{J} \mathrm{Maseko}^{1}$,Martin $\mathbf{G}$ Veller ${ }^{2}$ and Gavin R Norton ${ }^{1}$

${ }^{1}$ Cardiovascular Pathophysiology and Genomics Research Unit, School of Physiology, University of the Witwatersrand, Johannesburg, South Africa

${ }^{2}$ Department of Surgery, School of Medicine, Faculty of Health Sciences, University of the Witwatersrand, Johannesburg, South Africa

\begin{abstract}
Background: The extent to which Human Immunodeficiency Virus (HIV) is associated with increases in carotid Intima-Media Thickness (IMT) independent of conventional cardiovascular risk factors is unclear. Hence, we evaluated whether independent of conventional risk factors, an increased carotid IMT occurs in African HIV infected patients with chronic Critical Limb Ischemia (CLI).

Methods: Carotid IMT was measured in 217 sequentially recruited patients with CLI, 25 of whom were HIV positive and in 430 randomly selected controls from a community sample.

Results: As compared to HIV negative patients with CLI, HIV positive patients were younger (49 \pm 10 vs. $64 \pm$ 11 years, $p<0.0001)$ and had a markedly lower prevalence of hypertension and diabetes mellitus $(p<0.0001)$, but a similar proportion of patients smoked $(76 \%$ vs $67 \%)$. However, as compared to patients with CLI who were HIV negative, HIV positive patients had a similar increase in carotid IMT (HIV positive $=0.75 \pm 0.14 \mathrm{~mm}$; HIV negative= $0.79 \pm 0.14 \mathrm{~mm}$; Controls $=0.64 \pm 0.15, p<0.0001$ versus Controls) even after adjustments for age, sex and conventional risk factors (HIV positive $=0.75 \pm 0.13 \mathrm{~mm}$; HIV negative $=0.73 \pm 0.15 \mathrm{~mm}$, Controls $=0.66 \pm 0.15, p<$ 0.005). IMT was similarly increased in HIV positive patients with CLI as compared to controls when assessed in men, smokers, and black African patients only $(p<0.05-0.0001)$, or in those who were receiving highly active antiretrovira therapy $(n=12,0.74 \pm 0.10 \mathrm{~mm})$ as compared to those not receiving therapy $(0.75 \pm 0.15 \mathrm{~mm})$. As compared to controls, the age- sex- and conventional risk factor-adjusted odds of having an IMT $\geq 0.8 \mathrm{~mm}$ was similarly increased in patients with $\mathrm{CLI}$ who were HIV positive (odds ratio $=8.89, \mathrm{Cl}=2.79-28.32, \mathrm{p}=0.0002$ ) as those who were HIV negative (odds ratio $=2.70 \mathrm{Cl}=1.51-4.81, \mathrm{p}<0.001$ ).
\end{abstract}

Conclusion: These results suggest that despite being of a younger age, with or without conventional risk factor adjustments, marked increases in carotid IMT in HIV in Africa are a risk factor for CLI.

Keywords: Atherosclerosis; Carotid intima-media thickness; Human immunodeficiency virus

\section{Introduction}

There is increasing evidence that infection with Human Immunodeficiency Virus (HIV) is associated with occlusive arterial disease including myocardial infarction [1-3] and Peripheral Arterial Disease (PAD) [4,5]. A number of mechanisms may explain this relationship. Partly through antiretroviral therapy (protease inhibitors), patients with HIV infections have an increased prevalence of conventional cardiovascular risk factors [6]. The consequence may be endothelial dysfunction [7], and an enhanced degree of subclinical atherosclerosis as indexed by increases in carotid Intima-Media Thickness (IMT) [7-9]. However, vascular pathology in HIV may also occur through the virus infecting the arterial vasculature $[10,11]$, and increasing the chances of vascular inflammatory changes occurring either directly [12] or through co-infections [13-15]. Thus, increases in carotid IMT in HIV infected patients may not only index the degree of atherosclerosis, but also alternative large artery phenotypes [16]. The measurement of carotid IMT may therefore be particularly useful at predicting cardiovascular risk beyond conventional risk factors in HIV infected patients. Presently however there is considerable uncertainty as to whether increases in carotid IMT occur in HIV independent of conventional risk factors.

A recent meta-analysis [9] and a large study [8] not included in this prior meta-analysis [9] have suggested that the conventional risk factor-independent effects of HIV or antiretroviral therapy on common carotid IMT are modest and that to some extent these positive relationships reflect a publication bias [9]. Thus, increases in carotid IMT previously reported on in HIV [7-9] are more likely to be attributed to atherosclerosis mediated by conventional risk factors. However, there are no studies that have explored the relationship between HIV and carotid IMT in patients with clinical manifestations of advanced occlusive arterial disease. In this regard, recent studies have indicated that HIV infected patients in Africa presenting with occlusive arterial disease may have fewer risk factors for atherosclerosis, and angiographically or at surgery they are more frequently noted to have a lower atherosclerotic burden $[17,18]$. Consequently, in the present study, we aimed to compare the extent to which IMT is increased

*Corresponding author: Martin Brand and Angela J Woodiwiss, Departmen of Surgery, School of Medicine and Cardiovascular Pathophysiology and Genomics Research Unit, School of Physiology, University of the Witwatersrand Medical School, 7 York Road, Parktown, 2193, Johannesburg, South Africa, Tel: +27117172363; Fax: +27117172153; E-mail: martinbrand78@gmail.com angela. woodiwiss@wits.ac.za

Received July 12, 2012; Accepted September 10, 2012; Published September 13,2012

Citation: Brand M, Woodiwiss AJ, Michel F, Booysen HL, Majane OHI, et al (2012) Carotid Intima-Media Thickness in African Patients with Critical Lower Limb Ischemia Infected with the Human Immunodeficiency Virus. J AIDS Clinic Res 3:167. doi:10.4172/2155-6113.1000167

Copyright: (C) 2012 Brand M, et al. This is an open-access article distributed unde the terms of the Creative Commons Attribution License, which permits unrestricted use, distribution, and reproduction in any medium, provided the original author and source are credited. 
independent of conventional risk factors in African patients with Chronic Critical Lower Limb Ischemia (CLI) who are HIV infected as compared to those without evidence of HIV.

\section{Methods}

\section{Study groups}

The present study was conducted according to the principles outlined in the Helsinki declaration. The Committee for Research on Human Subjects of the University of the Witwatersrand approved the protocol (approval numbers: M11-08-29, M02-04-72, M07-04-69, M1204-108). Participants gave informed, written consent. Two-hundred and seventeen consecutive patients with CLI were recruited from the Divisions of Vascular Surgery at the Charlotte Maxeke Johannesburg Academic Hospital and the Chris Hani Baragwanath Hospital, Johannesburg, South Africa. The presence of chronic CLI was defined as the presence of ischemic pain at rest for more than two weeks, or the presence of ulcers or gangrene attributable to occlusive arterial disease [19]. Routine HIV serology (ELISA) was performed to determine HIV status and 25 patients with CLI were identified as having an HIV infection. Data obtained in patients with CLI were compared with data acquired in 430 participants older than 16 years, from randomly recruited nuclear families of black African descent with at least two parents or two siblings and living in the South West Township (SOWETO) of Johannesburg, South Africa, using the population census figures of 2001 [20-22]. In this regard, the Chris Hani Baragwanath Hospital serves the SOWETO community and patients attending the Charlotte Maxeke Johannesburg Academic Hospital are generally from a similar socioeconomic class and ethnic group as those living in the SOWETO community. Of the 1191 participants recruited, in a substudy consisting of 452 participants, 430 had complete and high quality common carotid intima-media thickness images and full lipid profile data.

\section{Demographic and clinical data}

A questionnaire was administered to obtain demographic information including each participant's medical history, the use of medication and tobacco and alcohol use [20-22]. Obesity was defined as a Body Mass Index (BMI) $\geq 30 \mathrm{~kg} / \mathrm{m}^{2}$. Blood tests were performed including fasting lipid profile and glycated hemoglobin $\left(\mathrm{HbA}_{1 \mathrm{C}}\right)$. A CD4 count was obtained in all HIV positive patients with CLI. Participants were considered to have diabetes mellitus if they had a fasting plasma glucose concentration $\geq 7 \mathrm{mmol} / 1$, or in whom glucose-lowering agents were prescribed. Brachial blood pressure (BP) was measured according to guidelines and taken as the mean of five measurements. Participants with a $\mathrm{BP} \geq 140 / 90 \mathrm{~mm} \mathrm{Hg}$ or in those receiving antihypertensive medication were considered to have hypertension. As all patients with CLI were receiving statins, dyslipidemia was diagnosed as the presence of either a raised triglyceride concentration $(\geq 1.7 \mathrm{mmol} / \mathrm{l})$ or a reduced High Density Lipoprotein (HDL) concentration $(<1.0 \mathrm{mmol} / \mathrm{l}$ for males and $<1.2 \mathrm{mmol} / \mathrm{l}$ for females).

\section{Carotid Intima-Media Thickness (IMT)}

Carotid IMT was determined using high resolution B-mode ultrasound (SonoCalc IMT, Sonosite Inc, Bothell, Washington) employing a linear array 7.5 $\mathrm{MHz}$ probe as previously described [22]. Images of at least $1 \mathrm{~cm}$ length of the far wall of the distal portion of the right common carotid artery from an optimal angle of incidence (defined as the longitudinal angle of approach where both branches of the internal and external carotid artery are visualized simultaneously) at least $1 \mathrm{~cm}$ proximal to the flow divider was obtained. Carotid
IMT measurements were determined using semi-automated borderdetection and quality control software. A carotid IMT $\geq 0.8 \mathrm{~mm}$ was considered to be pathological [23].

\section{Data analysis}

Database management and statistical analysis was performed using SAS software version 9.2 (SAS Institute Inc., Cary, NC). To determine differences in IMT multiple regression analysis was performed using a general linear model and the adjusted means (least squared means) were compared. To identify the conventional risk factors for CLI in HIV infected or HIV negative patients, and to determine the relationship between increased carotid IMT and CLI multivariate logistic regression analysis was performed. Included in the multivariate models were age, sex, hypertension, diabetes mellitus, smoking, triglyceride concentrations and HDL cholesterol concentrations. Probability values were further adjusted for non-independence of family members using the method of maximum likelihood as implemented by the mixed procedure as defined in the SAS package. As patients with CLI with an HIV infection were younger than those without evidence of an HIV infection, sensitivity analysis was conducted in HIV negative patients with CLI that were $<60$ years of age. As more men than women had CLI, the majority of patients with CLI smoked, in comparisons against the community sample, sensitivity analysis was also conducted in men only and smokers only. As HIV infected patients were of black African descent, whilst a proportion of HIV negative patients with CLI were white or Asian, sensitivity analysis was also conducted in black Africans only. Except for proportions, all data are shown as mean \pm SD.

\section{Results}

\section{Participant characteristics}

The demographic and clinical characteristics of the participants

\begin{tabular}{|c|c|c|c|}
\hline & \multirow[t]{2}{*}{$\begin{array}{l}\text { Community } \\
\text { sample }\end{array}$} & \multicolumn{2}{|c|}{$\begin{array}{c}\text { Critical lower limb ischemia } \\
\text { HIV infection }\end{array}$} \\
\hline & & Yes & No \\
\hline Sample size & 430 & 25 & 192 \\
\hline$\%$ Males & 35.3 & 84.0 & 69.3 \\
\hline Age (years) & $44 \pm 18$ & $49 \pm 10^{*}+\dagger$ & $64 \pm 11^{*}$ \\
\hline Black African (\%) & 100 & 92 & 59 \\
\hline Body mass index $\left(\mathrm{kg} / \mathrm{m}^{2}\right)$ & $29.5 \pm 8.3$ & $23.8 \pm 4.2^{*}$ & $26.3 \pm 5.2^{*}$ \\
\hline Waist circumference $(\mathrm{cm})$ & $90.6 \pm 18.1$ & $77.1 \pm 14.6^{*}$ & $85.8 \pm 17.1^{*}$ \\
\hline$\%$ Obese & 41.4 & $8.0^{*}$ & $19.3^{*}$ \\
\hline$\%$ Hypertensive & 44.7 & $16.0^{*} \dagger$ & $67.7^{*}$ \\
\hline \% Receiving antihypertensives & 26.1 & $16.0^{*} t$ & $67.7^{*}$ \\
\hline$\%$ With diabetes mellitus & 9.1 & $8.0 \dagger$ & $49.5^{*}$ \\
\hline \% Receiving glucose-lowering agents & 6.3 & 4.0 & 10.9 \\
\hline \% Receiving lipid-lowering agents & 0 & 100 & 100 \\
\hline Current smoker (\%) & 15.8 & $72.0^{*}$ & $66.7^{*}$ \\
\hline Regular alcohol (\%) & 22.8 & $68.0^{*}$ & $55.2^{*}$ \\
\hline Systolic blood pressure $(\mathrm{mm} \mathrm{Hg})$ & $128 \pm 22$ & $129 \pm 20 \dagger$ & $137 \pm 21^{*}$ \\
\hline Diastolic blood pressure $(\mathrm{mm} \mathrm{Hg})$ & $83 \pm 13$ & $79 \pm 12$ & $80 \pm 12$ \\
\hline Glycated hemoglobin (\%) & $6.05 \pm 1.29$ & $5.95 \pm 0.51$ & $7.74 \pm 2.56^{*}$ \\
\hline Total/HDL cholesterol & $3.49 \pm 1.17$ & $3.86 \pm 1.29$ & $4.06 \pm 1.74$ \\
\hline LDL cholesterol (mmol/l) & $2.65 \pm 0.90$ & $2.32 \pm 0.79$ & $2.16 \pm 0.99$ \\
\hline HDL cholesterol $(\mathrm{mmol} / \mathrm{l})$ & $1.41 \pm 0.45$ & $1.20 \pm 0.44$ & $1.09 \pm 0.46^{*}$ \\
\hline Triglycerides (mmol/l) & $1.16 \pm 0.66$ & $1.47 \pm 0.78^{*}$ & $1.35 \pm 0.64^{*}$ \\
\hline CD4 count $\left(\times 10^{6} / 1\right)$ & - & $325 \pm 122$ & \\
\hline
\end{tabular}

HIV- Human Immundeficiency Virus. * $p<0.0001$ versus community sample; $†$ $p<05, \dagger+p<0.001$ versus no evidence of HIV.

Table 1: Characteristics of participants. 
are shown in table 1. More men than women were noted to have CLI. As compared to randomly selected healthy participants from the community sample, patients with CLI who were HIV negative were older, fewer were of black African ancestry, and a higher prevalence of traditional risk factors, except for obesity, the prevalence of which was lower, was noted (Table 1). Whilst receiving statins, serum HDL cholesterol concentrations were markedly lower and triglyceride concentrations higher in HIV negative patients with CLI (Table 1).

\begin{tabular}{|c|c|c|}
\hline & HAART & non-HAART \\
\hline Sample size & 12 & 13 \\
\hline$\%$ Males & 83.3 & 84.6 \\
\hline Age (years) & $46 \pm 8$ & $52 \pm 11$ \\
\hline Black African (\%) & 100 & 84.6 \\
\hline Body mass index $\left(\mathrm{kg} / \mathrm{m}^{2}\right)$ & $23.0 \pm 5.0$ & $24.5 \pm 3.1$ \\
\hline$\%$ Obese & 8.3 & 7.7 \\
\hline$\%$ Hypertensive & 8.3 & 23.1 \\
\hline$\%$ With diabetes mellitus & 8.3 & 7.7 \\
\hline Current smoker (\%) & 75.0 & 69.0 \\
\hline Regular alcohol (\%) & 75.0 & 61.5 \\
\hline Systolic blood pressure (mm Hg) & $130 \pm 20$ & $129 \pm 21$ \\
\hline Diastolic blood pressure $(\mathrm{mm} \mathrm{Hg})$ & $82 \pm 10$ & $76 \pm 13$ \\
\hline Glycated hemoglobin (\%) & $5.95 \pm 0.30$ & $5.98 \pm 0.97$ \\
\hline Total/HDL cholesterol & $3.35 \pm 1.00$ & $4.15 \pm 1.30$ \\
\hline LDL cholesterol $(\mathrm{mmol} / \mathrm{l})$ & $2.10 \pm 0.73$ & $2.53 \pm 0.83$ \\
\hline HDL cholesterol $(\mathrm{mmol} / \mathrm{l})$ & $1.36 \pm 0.53$ & $1.06 \pm 0.27$ \\
\hline Triglycerides (mmol/l) & $1.47 \pm 0.73$ & $1.46 \pm 0.85$ \\
\hline CD4 count $\left(x 10^{6} / I\right)$ & $334 \pm 95$ & $316 \pm 149$ \\
\hline Carotid IMT (mm) & $0.74 \pm 0.10$ & $0.76 \pm 0.14$ \\
\hline Duration of treatment (years) & $1.2 \pm 0.9($ range 0.3 to 1.5$)$ & - \\
\hline
\end{tabular}

HIV- Human Immundeficiency Virus; IMT- Intima-Media Thickness.

Table 2. Characteristics of treated (HAART) versus non-treated (non-HAART) $\mathrm{HIV}+$ patients with critical limb ischemia.
More patients with as compared to without an HIV infection with CLI were of black African ancestry (Table 1). Patients with CLI infected with HIV had a markedly lower prevalence of traditional risk factors as compared to HIV negative patients with CLI, except for smoking, the prevalence of which was similar in HIV infected patients with CLI (Table 1). As compared to healthy participants, patients with CLI infected with HIV had a markedly lower prevalence of hypertension and obesity and more patients smoked (Table 1). However, the prevalence of diabetes mellitus was similar to the control group (Table 1). As compared to the control group, whilst receiving statins, patients with CLI infected with HIV had higher triglyceride concentrations, although the mean values were not higher than accepted international thresholds (Table 1). No differences in triglyceride concentrations were noted between the HIV infected and the HIV negative patients with CLI.

The characteristics of the 12 HIV infected patients receiving Highly Active Anti Retroviral Therapy (HAART) were similar to those not receiving therapy (Table 2). In the clinics at Charlotte Maxeke Johannesburg Academic Hospital and Chris Hani Baragwanath Hospital, Johannesburg, South Africa, the current HAART first-line therapy consists of 3 agents, namely 2 nucleoside reverse transcriptase inhibitors and 1 non-nucleoside reverse transcriptase inhibitor. None of the patients were receiving protease inhibitors as they are not used as first-line therapy.

\section{Comparison of conventional risk factors between patients with $\mathrm{CLI}<60$ years without evidence of an HIV infection}

As compared to patients with CLI and HIV infection (Table 1), a greater proportion of HIV negative patients with CLI $<60$ years of age ( $\mathrm{n}=64$, mean age $=51.4 \pm 7.2$ years, $\mathrm{p}=0.31$ versus patients with CLI and an HIV infection) had hypertension $(60.9 \%, \mathrm{p}<0.0005)$ and diabetes mellitus (56.3\%, $\mathrm{p}<0.0001)$. As compared to patients with CLI and an HIV infection (Table 1) a similar proportion of HIV negative patients

\begin{tabular}{|c|c|c|c|c|c|}
\hline \multirow[t]{2}{*}{ CLI vs } & \multirow[t]{2}{*}{ Subgroup (n) } & \multicolumn{4}{|c|}{ Odds ratios (OR) (95\% Confidence intervals) } \\
\hline & & Unadjusted & $p$ value & Adjusted* & $p$ value \\
\hline \multirow[t]{4}{*}{ Smoking } & HIV- (192) & $10.70(7.16-15.83)$ & $<0.0001$ & $10.12(6.01-17.08)$ & $<0.0001$ \\
\hline & HIV- < 60 yrs (64) & $10.90(6.09-19.52)$ & $<0.0001$ & $7.75(4.12-14.55)$ & $<0.0001$ \\
\hline & HIV- $\geq 60$ yrs (128) & $10.52(6.72-16.49)$ & $<0.0001$ & $12.84(6.74-24.47)$ & $<0.0001$ \\
\hline & $\mathrm{HIV}+(25)$ & $16.86(6.50-43.75)$ & $<0.0001$ & 10.87(3.96-29.78) & $<0.0001$ \\
\hline \multirow[t]{4}{*}{ Hypertension } & HIV- (192) & $2.60(1.82-3.72)$ & $<0.0001$ & $0.76(0.47-1.21)$ & $=0.50$ \\
\hline & HIV-< 60 yrs $(64)$ & $1.93(1.13-3.31)$ & $<0.05$ & $1.15(0.62-2.13)$ & $=0.06$ \\
\hline & HIV- $\geq 60$ yrs(128) & $3.05(1.99-4.69)$ & $<0.0001$ & $0.44(0.25-0.79)$ & $<0.05$ \\
\hline & $\mathrm{HIV}+(25)$ & $0.24(0.08-0.70) \dagger$ & $<0.0001$ & $0.12(0.04-0.40) \dagger$ & $<0.01$ \\
\hline \multirow[t]{4}{*}{ DM } & HIV- (192) & $9.82(6.36-15.16)$ & $<0.0001$ & $6.71(4.0-11.3)$ & $<0.0001$ \\
\hline & HIV-<60 yrs (64) & $12.89(7.12-23.53)$ & $<0.0001$ & $15.06(7.41-30.60)$ & $<0.0001$ \\
\hline & HIV- $\geq 60$ yrs (128) & $8.57(5.31-13.84)$ & $<0.0001$ & $3.93(2.10-7.14)$ & $<0.0001$ \\
\hline & $\mathrm{HIV}+(25)$ & $0.87(0.20-3.84) \dagger$ & $=0.86$ & $0.95(0.20-4.54)$ & $=0.60$ \\
\hline \multirow[t]{4}{*}{ Increased TG } & HIV- (192) & $1.56(1.03-2.37)$ & $<0.05$ & $0.88(0.54-1.43)$ & $=0.59$ \\
\hline & HIV- < 60 yrs (64) & $2.47(1.38-4.43)$ & $<0.005$ & $1.91(1.02-3.58)$ & $<0.05$ \\
\hline & HIV- $\geq 60$ yrs (128) & $1.19(0.72-1.98)$ & $=0.49$ & $0.47(0.26-0.86)$ & $<0.05$ \\
\hline & $\mathrm{HIV}+(25)$ & $0.69(0.20-2.37)$ & $=0.55$ & $0.53(0.15-1.92)$ & $=0.28$ \\
\hline \multirow{4}{*}{$\begin{array}{l}\text { Decreased HDL } \\
\text { cholestrol }\end{array}$} & HIV- (192) & $3.17(2.18-4.59)$ & $<0.0001$ & $3.73(2.34-5.95)$ & $<0.0001$ \\
\hline & HIV-<60 yrs (64) & $4.37(2.50-7.63)$ & $<0.0001$ & $5.81(3.11-10.86)$ & $<0.0001$ \\
\hline & HIV- $\geq 60$ yrs (128) & $2.69(1.76-4.13)$ & $<0.0001$ & $2.66(1.54-4.60)$ & $=0.001$ \\
\hline & $\mathrm{HIV}+(25)$ & $2.75(1.17-6.47)$ & $<0.05$ & $3.76(1.51-9.36)$ & $<0.01$ \\
\hline
\end{tabular}

DM- Diabetes Mellitus; TG- Tryglycerides; HDL cholest- High Density Lipoprotein Fraction of Cholesterol. *Age and sex-adjusted. Probability values were further adjusted for non-independence of family members. Increased TG indicates values $\geq 1.7 \mathrm{mmol} / \mathrm{l}$. Decreased $\mathrm{HDL}$ cholesterol indicates values $<1.0 \mathrm{mmol} / \mathrm{l}$ for males and $<1.2 \mathrm{mmol} / \mathrm{l}$ for females. $\uparrow p<0.001$ vs OR for HIV-group.

Table 3. Conventional cardiovascular risk factors associated with Critical Limb Ischemia (CLI) in patients with $(+)(n=25)$ or without $(-)(n=192)$ a Human Immunodeficiency Virus (HIV) infection as compared to a community sample $(n=430)$. 


\begin{tabular}{|c|c|c|c|c|c|}
\hline \multirow[t]{2}{*}{ Adjustments } & \multirow[t]{2}{*}{ Community sample } & \multicolumn{2}{|c|}{ CLI HIV infection } & \multicolumn{2}{|c|}{ p-values community sample vs } \\
\hline & & Yes & No & $\mathrm{HIV+}$ & HIV- \\
\hline & & \multicolumn{4}{|c|}{ All participants } \\
\hline Sample size & $n=430$ & $n=25$ & $n=192$ & & \\
\hline Unadjusted & $0.63 \pm 0.14$ & $0.75 \pm 0.14$ & $0.79 \pm 0.14$ & $<0.0001$ & $<0.0001$ \\
\hline Age- and sex- & $0.66 \pm 0.12$ & $0.75 \pm 0.13$ & $0.73 \pm 0.14$ & $<0.0005$ & $<0.0001$ \\
\hline \multirow[t]{2}{*}{ Age-, sex- and other* } & $0.66 \pm 0.15$ & $0.75 \pm 0.13$ & $0.73 \pm 0.15$ & $<0.0005$ & $=0.0001$ \\
\hline & & \multicolumn{4}{|c|}{ HIV negative patients with CLI<60 years old } \\
\hline Sample size & $n=430$ & $n=25$ & $n=64$ & & \\
\hline Unadjusted & $0.63 \pm 0.14$ & $0.75 \pm 0.14$ & $0.79 \pm 0.14$ & $<0.0001$ & $<0.0001$ \\
\hline Age and sex-adjusted & $0.64 \pm 0.12$ & $0.73 \pm 0.12$ & $0.75 \pm 0.12$ & $<0.0005$ & $<0.0001$ \\
\hline \multirow[t]{2}{*}{ Age-, sex- and other ${ }^{*}$} & $0.64 \pm 0.12$ & $0.72 \pm 0.13$ & $0.76 \pm 0.15$ & $<0.0005$ & $<0.0001$ \\
\hline & & \multicolumn{4}{|c|}{ Men } \\
\hline Sample size & $n=152$ & $n=21$ & $n=133$ & & \\
\hline Unadjusted & $0.64 \pm 0.16$ & $0.75 \pm 0.14$ & $0.79 \pm 0.14$ & $<0.005$ & $<0.0001$ \\
\hline Age- and sex- & $0.68 \pm 0.16$ & $0.75 \pm 0.13$ & $0.73 \pm 0.14$ & $=0.017$ & $<0.005$ \\
\hline \multirow[t]{2}{*}{ Age-, sex- and other ${ }^{*}$} & $0.68 \pm 0.17$ & $0.76 \pm 0.15$ & $0.75 \pm 0.17$ & $=0.014$ & $<0.05$ \\
\hline & & \multicolumn{4}{|c|}{ Smokers } \\
\hline Sample size & $n=68$ & $n=19$ & $n=128$ & & \\
\hline Unadjusted & $0.63 \pm 0.14$ & $0.76 \pm 0.14$ & $0.80 \pm 0.14$ & $<0.0005$ & $<0.0001$ \\
\hline Age- and sex- & $0.66 \pm 0.16$ & $0.77 \pm 0.14$ & $0.78 \pm 0.15$ & $<0.005$ & $<0.0001$ \\
\hline \multirow[t]{2}{*}{ Age-, sex- and other* } & $0.66 \pm 0.17$ & $0.77 \pm 0.15$ & $0.78 \pm 0.16$ & $<0.005$ & $<0.0001$ \\
\hline & & \multicolumn{4}{|c|}{ Black Africans } \\
\hline Sample size & $n=430$ & $n=23$ & $n=113$ & & \\
\hline Unadjusted & $0.63 \pm 0.14$ & $0.75 \pm 0.14$ & $0.79 \pm 0.14$ & $<0.0001$ & $<0.0001$ \\
\hline Age- and sex- & $0.66 \pm 0.12$ & $0.75 \pm 0.12$ & $0.71 \pm 0.13$ & $<0.0001$ & $<0.0005$ \\
\hline Age-, sex- and other* & $0.65 \pm 0.12$ & $0.75 \pm 0.13$ & $0.72 \pm 0.15$ & $<0.0005$ & $<0.0005$ \\
\hline
\end{tabular}

*Additional adjustments are for hypertension, diabetes mellitus, smoking (except for analysis conducted in smokers only), triglyceride concentrations and HDL cholesterol concentrations. Probability values were further adjusted for non-independence of family members. No differences were noted in groups with or without HIV infection.

Table 4. Comparisons of unadjusted and multivariate-adjusted carotid intima-media thickness (IMT) values in patients with critical limb ischemia (CLI) with (+) or without (-) a human immunodeficiency virus (HIV) infection and in apparently healthy participants from a community sample.

with CLI $<60$ years of age smoked $(56.3 \%, \mathrm{p}=0.23)$.

\section{Conventional cardiovascular risk factors associated with CLI in patients with versus without evidence of HIV infection}

Table 3 shows the unadjusted and age- and sex-adjusted odds of conventional cardiovascular risk factors increasing the chances of CLI. As compared to the control group, in patients with HIV infection, smoking, and dyslipidemia as defined by reduced HDL cholesterol concentrations were the only conventional risk factors associated with CLI. In contrast, in HIV negative patients, irrespective of whether or not they were $<60$ years of age; smoking, diabetes mellitus, hypertension and dyslipidemia as defined by raised triglyceride concentrations (in patients $<60$ years of age) and a low HDL cholesterol concentration were all associated with CLI. The odds of hypertension being associated with CLI were reduced in patients with an HIV infection as compared to patients without evidence of an HIV infection.

\section{Carotid intima-media thickness}

Table 4 shows unadjusted, and multivariate adjusted carotid IMT values. Without or with age- and sex-adjustments or age-, sex-, and conventional risk factor- adjustments, carotid IMT was markedly increased in both the HIV infected and HIV negative patients with CLI. Sensitivity analysis conducted in HIV negative patients with CLI $<60$ years of age, men only, smokers only and in black Africans only, showed similar differences as noted in all participants. Furthermore, multivariate adjusted IMT values in HIV positive patients with CLI who were $<60$ years of age $(0.73 \pm 0.12 \mathrm{~mm})$ who had a mean \pm SD age of $45 \pm 6$ years were higher than multivariate adjusted IMT values in all participants from the community sample $(0.64 \pm 0.11 \mathrm{~mm}, \mathrm{p}<0.0005)$ who had a mean \pm SD age of $44 \pm 18$ years. Importantly, no differences in IMT were noted in patients with CLI with as compared to without evidence of an HIV infection. No differences were noted in the carotid IMT in patients receiving HAART $(\mathrm{n}=12,0.74 \pm 0.10 \mathrm{~mm})$ as compared to those not receiving HAART $(0.75 \pm 0.15 \mathrm{~mm})$.

\section{An increased carotid intima-media thickness as a risk factor for CLI in HIV infected versus HIV negative patients}

Table 5 shows the unadjusted; sex- and age-adjusted; and sex-, age- and conventional risk factor-adjusted odds of having an increased carotid IMT in patients with CLI as compared to controls in HIV infected and HIV negative patients. As compared to controls the presence of an increased carotid IMT increased the odds of having CLI irrespective of whether patients were HIV infected or HIV negative. As compared to controls, the odds of having an increased IMT in patients with CLI who were HIV infected were similar to those who were not infected with HIV. In sensitivity analysis these results were consistent when assessing HIV negative patients with CLI $<60$ years of age, men only, smokers only, and in black Africans only. Furthermore, as compared to all participants from the community sample who had a mean \pm SD age of $44 \pm 18$ years, an increased multivariate adjusted odds of having an increased carotid IMT in HIV positive patients with CLI who were $<60$ years of age and who had a mean \pm SD age of $45 \pm 6$ years was 11.54 (confidence intervals $=3.29-40.54, \mathrm{p}<0.0001$ ).

\section{Discussion}

The main findings of the present study are as follows. As compared to patients with CLI who were HIV negative and had a number of conventional cardiovascular risk factors associated with CLI, patients 


\begin{tabular}{|c|c|c|c|c|c|c|c|}
\hline \multicolumn{2}{|c|}{ Carotid IMT $\geq 0.8$ vs } & OR $(95 \% \mathrm{Cl})$ & $p$ value & OR $(95 \% \mathrm{Cl})$ & $p$ value & OR $(95 \% \mathrm{Cl})$ & $p$ value \\
\hline \multicolumn{8}{|c|}{ All participants } \\
\hline \multicolumn{2}{|c|}{ Adjustments } & \multicolumn{2}{|c|}{ Unadjusted } & \multicolumn{2}{|c|}{ Age- and sex } & \multicolumn{2}{|c|}{ Age-, sex- and conventional risk factors* } \\
\hline \multirow{2}{*}{ CLI in patients } & HIV- & $6.34(4.18-9.61)$ & $<0.0001$ & $2.89(1.79-4.66)$ & $<0.0001$ & $2.70(1.51-4.81)$ & $<0.0001$ \\
\hline & $\mathrm{HIV}+$ & $7.52(3.24-17.44)$ & $<0.0001$ & $7.69(2.92-20.25)$ & $<0.0001$ & $8.89(2.79-28.32)$ & $<0.0001$ \\
\hline \multicolumn{8}{|c|}{ HIV negative patients with $C L I<60$ years old } \\
\hline \multicolumn{2}{|c|}{ Adjustments } & \multicolumn{2}{|c|}{ Unadjusted } & \multicolumn{2}{|c|}{ Age-, and sex- } & \multicolumn{2}{|c|}{ Age-, sex- and conventional risk factors* } \\
\hline CLI in patients & HIV- & $5.95(3.33-10.63)$ & $<0.0001$ & $5.16(2.64-10.09)$ & $<0.0001$ & $4.77(1.91-11.88)$ & $<0.0001$ \\
\hline \multicolumn{8}{|c|}{ Men } \\
\hline \multicolumn{2}{|c|}{ Adjustments } & \multicolumn{2}{|c|}{ Unadjusted } & \multicolumn{2}{|l|}{ Age- } & \multicolumn{2}{|c|}{ Age-, and conventional risk factors ${ }^{*}$} \\
\hline \multirow{2}{*}{ CLI in patients } & HIV- & $4.82(2.72-8.57)$ & $<0.0001$ & $2.73(1.46-5.13)$ & $<0.005$ & $1.88(0.80-4.46)$ & $=0.15$ \\
\hline & $\mathrm{HIV}+$ & $6.86(2.59-18.15)$ & $=0.0001$ & $8.34(2.81-24.76)$ & $<0.0001$ & $8.83(2.10-37.21)$ & $=0.001$ \\
\hline \multicolumn{8}{|c|}{ Smokers } \\
\hline \multicolumn{2}{|c|}{ Adjustments } & \multicolumn{2}{|c|}{ Unadjusted } & \multicolumn{2}{|c|}{ Age, and sex- } & \multicolumn{2}{|c|}{ Age-, sex- and conventional risk factors (except smoking) } \\
\hline \multirow{2}{*}{ CLI in patients } & HIV- & $10.12(3.82-26.82)$ & $<0.0001$ & $6.69(2.25-19.92)$ & $<0.0005$ & $5.03(1.61-15.74)$ & $<0.01$ \\
\hline & $\mathrm{HIV}+$ & $14.00(3.89-50.39)$ & $<0.0001$ & $8.77(2.15-35.72)$ & $<0.0005$ & $11.29(1.74-73.10)$ & $<0.01$ \\
\hline \multicolumn{8}{|c|}{ Black African } \\
\hline \multicolumn{2}{|c|}{ Adjustments } & \multicolumn{2}{|c|}{ Unadjusted } & \multicolumn{2}{|c|}{ Age, and sex- } & \multicolumn{2}{|c|}{ Age-, sex- and conventional risk factors* } \\
\hline \multirow{2}{*}{ CLI in patients } & HIV- & $6.47(4.01-10.44)$ & $<0.0001$ & $2.69(1.56-4.66)$ & $<0.001$ & $2.96(1.45-6.04)$ & $<0.005$ \\
\hline & $\mathrm{HIV}+$ & $7.47(3.12-17.87)$ & $<0.0001$ & $9.00(3.32-24.40)$ & $<0.0001$ & $9.90(3.01-32.60)$ & $<0.0001$ \\
\hline
\end{tabular}

OR- Odds Ratio; Cl- Confidence Interval. See Table 4 for sample sizes in subgroups. *Additional adjustments are for hypertension, diabetes mellitus, smoking, triglyceride concentrations and HDL cholesterol concentrations. Probability values were further adjusted for non-independence of family members.

Table 5: Relationship between an increased carotid intima-media thickness (IMT $\geq 0.8 \mathrm{~mm})$ with critical limb ischemia (CLI) in patients with (+) ( $\mathrm{n}=25)$ or without $(-)(\mathrm{n}=192)$ a human immunodeficiency virus (HIV) infection as compared to a community sample $(n=430)$.

with CLI who were HIV infected were approximately 15 years younger and other than smoking and dyslipidemia, had no other conventional risk factors (no diabetes mellitus or hypertension) for atherosclerosis. Despite the lower age and conventional risk factor profiles in patients with CLI who were HIV positive as compared to those who were HIV negative, patients with CLI who were HIV positive had similar unadjusted and age- and sex-adjusted increases in carotid IMT or the odds of having an increased IMT as compared to randomly selected participants from a community sample. With further adjustments for alternative conventional risk factors, patients with CLI infected with HIV retained as high a carotid IMT and odds of an increased IMT as HIV negative patients with CLI. Moreover, in sensitivity analysis the increased carotid IMT and odds of an increased IMT in HIV infected patients with CLI was consistent across a number of groups including men only, smokers only and those of black African descent. Furthermore, the increased IMT and odds of an increased IMT in HIV infected patients with CLI was comparable with the increased IMT and odds of an increased IMT in HIV negative patients with CLI $<60$ years of age. The use of HAART did not influence the extent of the increase in carotid IMT in patients with CLI infected with HIV.

Although previous studies have demonstrated that HIV is associated with an increased carotid IMT $[7,8]$, the extent to which this occurs independent of conventional risk factors is controversial $[7,8]$. The present study is the first to show that in advanced occlusive arterial disease, such as occurs in CLI, HIV infected patients who are a distinct group both demographically (younger age) and with respect to the absence of important conventional cardiovascular risk factors (hypertension and diabetes mellitus) except smoking and dyslipidemia, have as extensive an increase in common carotid IMT as patients with CLI who are HIV negative. Even with adjustments for age, smoking and the presence of dyslipidemia, the increases in carotid IMT in patients with CLI and HIV infection were equivalent to that observed in HIV negative patients with CLI. As triglyceride concentrations were similarly increased in the HIV positive and negative patients with CLI, it is unlikely that the increased carotid IMT in HIV positive patients could be attributed to co-infection-induced hypertriglyceridaemia. In addition, in the present study, as none of the HIV infected patients were receiving protease inhibitors, the use of protease inhibitors could not account for the increased carotid IMT in the HIV positive patients with CLI. The relationship between carotid IMT and CLI in HIV infected patients in the present study therefore suggests that despite being of a younger age, independent of conventional cardiovascular risk factors, carotid IMT may serve as a strong risk factor for occlusive arterial disease in HIV.

The characteristics of the HIV positive patients with CLI in the present study were similar to those reported on in prior studies describing the presence of occlusive arterial disease in HIV infected African patients $[17,18]$. In this regard, as with these previous studies $[17,18]$, HIV positive patients with occlusive arterial disease were younger and had considerably less conventional risk factors other than smoking than HIV negative patients. In prior studies conducted in HIV positive patients with occlusive arterial disease, the burden of atherosclerosis was considerably lower than HIV negative patients $[17,18]$. Thus, in the present study it is also possible that the burden of atherosclerosis was considerably lower in the HIV positive as compared to the HIV negative patients with CLI. It is therefore unlikely that the similarity in the extent of the increase in carotid IMT in HIV positive as compared to negative patients can be attributed to a comparable degree of carotid atherosclerosis. Rather, the extensive increase in carotid IMT in HIV positive patients is likely to reflect in-part a carotid phenotype other than typical atherosclerosis. In this regard, there is increasing evidence to support the view that carotid IMT is a measure of arterial phenotypes other than atherosclerosis [16].

Possible explanations for increases in IMT beyond that which can be explained by atherosclerotic risk factors require consideration. In this regard, a vascular inflammatory process mediated by cytomegalovirus (CMV)-induced immune responses may occur in HIV $[13,14]$. Indeed, CMV has been demonstrated to produce intimal thickening in experimental studies [15] and after controlling for CMV- 
specific immune responses, HIV-related increases in carotid IMT are abolished [14]. Alternatively, HIV may be associated with an increased arterial inflammatory infiltrate [12] possibly mediated by increased concentrations of chemoattractant proteins such as monocyte chemoattractant protein 1 [24].

In the present study we evaluated common rather than internal carotid artery IMT. In this regard, a previous large study has provided evidence to show that as compared to data obtained in the common carotid artery, data obtained in the internal carotid artery shows a markedly greater conventional risk factor-independent effect of HIV on IMT [8]. Thus, the use of the common carotid artery may underestimate the quantitative effect of HIV independent of conventional risk factors. The design of the present study nevertheless provides an inherent control for this limitation as we were able to compare IMT in the common carotid artery in HIV infected patients with CLI to that noted in patients with advanced occlusive arterial disease (CLI) without evidence of HIV. In this regard, the extent of the increase in IMT in the common carotid was equivalent in the two groups.

When adjusting for the adverse effects of conventional cardiovascular risk factors on carotid IMT, we could not adjust for absolute blood pressure or low density lipoprotein cholesterol concentrations as continuous traits as a high proportion of patients with CLI were receiving antihypertensive and lipid lowering therapy. Thus we cannot discount the possibility of residual confounding effects explaining the independent relationships between CLI and carotid IMT in HIV infected patients. In this regard however, the same limitation applies to the HIV negative group with CLI as applies to the HIV infected patients with CLI, and yet the carotid IMT values in both of these groups were similarly increased as compared to the control group. Hence, we believe that by studying a group of patients with CLI without evidence of HIV infection, the chance of residual confounding effects produced by differences in blood pressure or lipid profiles is unlikely to have significantly contributed to the conventional risk factorindependent relations between CLI and carotid IMT in HIV infected patients.

In the present study we noted that the majority (76\%) of patients with CLI who were HIV infected were smokers. These data are consistent with the high prevalence of smoking in HIV infected individuals with occlusive arterial disease in previous reports [3,18,25,26]. Smoking therefore represents an important confounder when assessing relationships between HIV and carotid IMT. Although we showed similar increases in carotid IMT in HIV infected patients with CLI as compared to those without evidence of HIV infection after adjustments for smoking and in sensitivity analysis conducted in smokers only, the duration of smoking could not be adjusted for. However, as HIV infected patients with CLI were 15 years younger on average than HIV negative patients, it is more likely that those without HIV smoked for a longer duration and hence we are likely to have biased against the results of the present study.

The limitations of the present study are as follows. This was a cross-sectional study and hence no conclusions regarding cause and effect between HIV and carotid IMT can be drawn. It is therefore still possible that unidentified risk factors for carotid IMT other than the HIV infection could still account for the similarity in the increase in carotid IMT in patients with CLI infected as compared to uninfected with HIV. Only a longitudinal study will resolve this issue, but with the introduction of HAART as part of in routine clinical care in patients with HIV infections, a carefully controlled longitudinal study is not ethically feasible. Second, inherent in any study that assesses patients with advanced occlusive arterial disease indexed by the presence of CLI, the interpretation of the results of the present study are limited by the small number of patients with CLI identified as having an HIV infection (25 of 217 patients). However, the selection of sequential patients with CLI was necessary to attempt to avoid a selection bias. Moreover, the study sample reported on probably reflects as large a sample as one could expect given the advanced nature of the occlusive arterial disease studied and the overall prevalence of HIV. Importantly, the study was statistically powered to show the effects explored; we have a $<1$ to $1 \%$ chance of a type I error. As a consequence of the stigma linked to HIV infection in South Africa, we also could not perform tests of HIV status in the apparently healthy community sampled. Based on current trends of HIV prevalence in this community, we predict that approximately $15 \%$ of the community would be HIV infected [27]. However, this would have biased against the results of the present study as the mean carotid IMT in the apparently healthy community may have been lower than that identified if we had excluded individuals with HIV infection. Last, we did not assess plaque scores or measures of plaque volume to assess the extent of the atherosclerotic burden in the present study. This may have assisted in distinguishing between the atherosclerotic versus non-atherosclerotic carotid phenotype [16].

In conclusion, in the present study we show that independent of conventional cardiovascular risk factors or HAART, IMT in the common carotid artery is increased to a similar extent in patients with CLI with as compared to those without an HIV infection. This was noted despite patients with CLI who were HIV infected being of a younger age (on average 15 years younger) and having fewer conventional risk factors for cardiovascular disease. Indeed, in contrast to the high prevalence of hypertension and diabetes mellitus in HIV negative patients with CLI even in those $<60$ years of age; in those patients with CLI who were HIV infected neither hypertension, nor diabetes mellitus were risk factors for CLI with or without adjustments for sex and age. However, patients with CLI whom were HIV infected did have as high a prevalence of smoking and possibly dyslipidemia as patients with CLI without evidence of HIV, but these factors were adjusted for in multivariate models. These results therefore suggest that an increased carotid IMT may be a strong independent risk factor for CLI in HIV infected African patients.

\section{Acknowledgements}

This work was supported by the Medical Research Council of South Africa the Circulatory Disorders Research Trust, the University Research Council of the University of the Witwatersrand, the National Research Foundation of South Africa, and the Carnegie Trust. MB is a recipient of a Carnegie Clinical Fellowship.

\section{References}

1. Triant VA, Lee H, Hadigan C, Grinspoon SK (2007) Increased acute myocardia infarction rates and cardiovascular risk factors among patients with human immunodeficiency virus disease. J Clin Endocrinol Metab 92: 2506-2512.

2. Currier JS, Taylor A, Boyd F, Dezii CM, Kawabata H, et al. (2003) Coronary heart disease in HIV-infected individuals. J Acquir Immune Defic Syndr 33: 506512.

3. Klein D, Hurley LB, Wuesnberry CP Jr, Sidney S (2002) Do protease inhibitors increase the risk for coronary heart disease in patients with HIV-1 infection? J Acquir Immune Def Syndr 30: 471-477.

4. Periard D, Cavassini M, Taffé P, Chevalley M, Senn L, et al.( 2008) High prevalence of peripheral arterial disease in HIV-infected persons. Clin Infect Dis 46: 761-767.

5. Ye Y, Zeng Y, Li X, Zhang S, Fang Q, et al. (2010) HIV infection: An independent risk factor of peripheral arterial disease. J Acquir Immune Defic Syndr 53: 276 278.

6. van Vonderen MG, Hassink EA, van Agtmael MA, Stehouwer CD, Danner 
Citation: Brand M, Woodiwiss AJ, Michel F, Booysen HL, Majane OHI, et al. (2012) Carotid Intima-Media Thickness in African Patients with Critical Lower Limb Ischemia Infected with the Human Immunodeficiency Virus. J AIDS Clinic Res 3:167. doi:10.4172/2155-6113.1000167

SA, et al. (2009) Increase in carotid artery intima-media thickness and arterial stiffness but improvement in several markers of endothelial function after initiation of antiretroviral therapy. J Infect Dis 199:1186-1194.

7. Hsue PY, Lo JC, Franklin A, Bolger AF, Martin JN, et al. (2004) Progression of atherosclerosis as assessed by carotid intima-media thickness in patients with HIV infection. Circulation 109: 1603-1608.

8. Grunfeld C, Delaney JA, Wanke C, Currier JS, Scherzer R, et al. (2009) Preclinical atherosclerosis due to HIV infection: Carotid intima-medial thickness measurements from the FRAM study. AIDS 23: 1841-1849.

9. Hulten E, Mitchell J, Scally J, Gibbs B, Villines TC (2009) HIV positivity, protease inhibitor exposure and subclinical atherosclerosis: a systematic review and meta-analysis of observational studies. Heart 95: 1826-1835.

10. Tabib A, Greenland T, Mercier I, Loire R, Mornex JF (1992) Coronary lesions in young HIV-positive subjects at necropsy. Lancet 340: 730-731.

11. Bobryshev YV (2000) Identification of HIV-1 in the aortic wall of AIDS patients. Atherosclerosis 152: 529-530.

12. Hsue PY, Hunt PW, Schnell A, Kalapus SC, Hoh R, et al. (2009) Role of vira replication, antiretroviral therapy, and immunodeficiency in HIV-associated atherosclerosis. AIDS 23: 1059-1067.

13. Sacre K, Hunt PW, Hsue PY, Maidji E, Martin JN, et al. (2012) A role for cytomegalovirus-specific CD4+CX3CR1 + T cells and cytomegalovirus-induced T-cell immunopathology in HIV-associated atherosclerosis. AIDS 26: 805-814.

14. Hsue PY, Hunt PW, Sinclair E, Bredt B, Franklin A, et al. (2006) Increased carotid intima-media thickness in HIV patients is associated with increased cytomegalovirus-specific T-cell responses. AIDS 20: 2275-2283.

15. Lemström K, Koskinen P, Krogerus L, Daemen M, Bruggeman C, et al. (1995) Cytomegalovirus antigen expression, endothelial cell proliferation, and intimal thickening in rat cardiac allografts after cytomegalovirus infection. Circulation 92: $2594-2604$

16. Spence JD (2006) Measurement of intima-media thickness vs. carotid plaque: uses in patient care, genetic research and evaluation of new therapies. Int $\mathrm{J}$ Stroke 1: 216-221.

17. Mulaudzi TV, Robbs JV, Pillay W, Pillay B, Moodley J, et al. (2005) Thrombectomy in HIV related peripheral arterial thrombosis: A preliminary report. Eur J Vasc Endovasc Surg 30: 102-106.

18. Becker AC, Sliwa K, Stewart S, Libhaber E, Essop AR, et al. (2010) Acute coronary syndromes in treatment-naïve black South Africans with human immunodeficiency virus infection. J Int Cardiol 23: 70-77.

19. Rutherford RB, Baker JD, Ernst C, Johnston KW, Porter JM, et al. (1997) Recommended standards for reports dealing with lower extremity ischemia: revised version. J Vasc Surg 26: 517-538.

20. Woodiwiss AJ, Molebatsi N, Maseko MJ, Libhaber E, Libhaber C, et al. (2009) Nurse-recorded auscultatory blood pressure at a single visit predicts target organ changes as well as ambulatory blood pressure. J Hypertens 27: 287-297.

21. Redelinghuys M, Norton GR, Scott L, Maseko MJ, Brooksbank R, et al. (2010) Relationship between urinary salt excretion and pulse pressure and central aortic hemodynamics independent of steady state pressure in the general population. Hypertension 56: 584-590.

22. Norton GR, Majane $\mathrm{OH}$, Maseko MJ, Libhaber C, Redelinghuys M, et al. (2012) Brachial blood pressure-independent relations between radial late systolic shoulder-derived aortic pressures and target organ changes. Hypertension 59 : 885-892.

23. Veller MG, Fisher CM, Nicolaides AN, Renton S, Geroulakos G, et al. (1993) Measurement of ultrasonic intima-media complex thickness in normal subjects. J Vasc Surg 17: 719-725.

24. Alonso-Villaverde C, Coll B, Parra S, Montero M, Calvo N, et al. (2004) Atherosclerosis in patients infected with HIV is influenced by a mutant monocyte chemoattractant protein-1 allele. Circulation 110: 2204-2209.

25. Saves M, Chene G, Ducimetiere P, Leport C, Le Moal G, et al. (2003) Risk factors for coronary heart disease in patients treated for human immunodeficiency virus infection compared with the general population. Clin Infect Dis 37: 292-298.

26. Friis-Moller N, Weber R, Reiss P, Thiebaut R, Kirk O, et al. (2003) Cardiovascula disease risk factors in HIV patients--association with antiretroviral therapy. Results from the DAD Study. AIDS 17: 1179-1193.

27. ljsselmuiden C, Evian C, Matjilla J, Steinberg M, Schneider H (1993) AIDS in South Africa. AIDS Soc 4: 10-11. 